\title{
Spatio-temporal permanence and plasticity of foraging trails in young and mature leaf-cutting ant colonies (Atta spp.)
}

\author{
Christian Kost*, Evandro Gama de Oliveira†, Tobias Aurelius Knoch $\ddagger$ and Rainer Wirth*1
}

\author{
* Plant Ecology and Systematics, Department of Biology, University of Kaiserslautern, P.O. Box 3049, 67653 Kaiserslautern, Germany \\ $\dagger$ †epartamento de Biologia Geral, Instituto de Ciências Biológicas, Universidade Federal de Minas Gerais, 30161-970 Belo Horizonte, MG, Brazil \\ $\ddagger$ German Cancer Research Center, Im Neuenheimer Feld 280, D-69120 Heidelberg, Germany and Kirchhoff Institute for Physics, Ruperto-Carola University \\ of Heidelberg, Im Neuenheimer Feld 227, D-69120 Heidelberg, Germany \\ (Accepted 29 March 2005)
}

\begin{abstract}
The distribution and formation of foraging trails have largely been neglected as factors explaining harvesting patterns of leaf-cutting ants. We applied fractal analysis, circular, and conventional statistics to published and newly recorded trail maps of seven Atta colonies focusing on three aspects: permanence, spatio-temporal plasticity and colony life stage. In the long term, trail patterns of young and mature Atta colonies revealed that foraging activities were focused on distinct, static sectors that made up only parts of their potentially available foraging range. Within these foraging sectors, trails were typically ephemeral and highly variable in space and time. These ephemeral trails were concentrated around permanent trunk trails in mature and around nest entrances in young colonies. Besides these similarities, the comparison of trail systems between the two life stages indicated that young colonies exploited fewer leaf sources, used smaller and less-complex systems of foraging trails, preferred different life forms as host plants, and switched hosts more often compared with mature colonies. Based on these analyses, we propose a general hypothesis which describes the foraging pattern in Atta as a result of initial foraging experiences, spatio-temporal distribution of suitable host plants, energetic constraints, and other factors such as seasonality and interspecific predation.
\end{abstract}

Key Words: Atta, foraging pattern, fractal dimension, leaf-cutting ants, optimal foraging, trunk trail system

\section{INTRODUCTION}

Leaf-cutting ants of the genus Atta (Hymenoptera, Formicidae, Attini) are restricted to the New World. They are amongst the most abundant and polyphagous herbivorous insects known (Cherrett 1968, 1983; Lugo et al. 1973, Rockwood \& Hubbell 1987) that affect forest structure, composition and dynamics (Farji-Brener \& Silva 1995, Rao et al. 2001, Wirth et al. 2003). Leafcutting ants are characterized by the sophisticated habit of culturing and consuming a symbiotic fungus, which is the sole food source for larval ants. The diet of foraging workers, however, appears to consist mostly of plant sap consumed during leaf cutting (Littledyke \& Cherrett 1976).

Atta colonies use an extensive system of foraging trails to harvest large amounts of leaf material for the growth of their fungus. These cleared paths direct foragers

\footnotetext{
${ }^{1}$ Corresponding author. Email: wirth@rhrk.uni-kl.de
}

through the littered forest floor to their host plants, thus enhancing foraging speed 4- to 10-fold as compared with uncleared ground (Rockwood \& Hubbell 1987). Furthermore, they mark the foraging territory that is defended against competing colonies, thereby reducing the aggression between neighbouring colonies (Fowler \& Stiles 1980, Hölldobler \& Lumsden 1980). Despite their striking appearance and importance for foraging and territorial defence, little is known about the origin, maintenance and persistence of trail systems in Atta (but see Shepherd 1982).

Repeated observations of an area-restricted search of foraging Atta ants, which is concentrated on the vicinity or ends of major trails (Farji-Brener \& Sierra 1993, Fowler \& Robinson 1979, Stradling 1978) indicated that foraging trails reflect the patchy distribution of highquality resources in space and time (Fowler \& Stiles 1980). Farji-Brener \& Sierra (1993) addressed this issue empirically and proposed a leaf harvest rotating around the nest with an unpredictable covering of its vicinity based on the monitoring of the foraging trail system of a 
single adult colony of Atta cephalotes over 7 consecutive days. Although the trail system mirrors harvesting patterns of Atta, continuing studies addressing the formation, development and spatio-temporal distribution of foraging trails in Atta are lacking. Moreover, the life stage of an Atta colony has never been taken into account to explain the observed foraging patterns.

The aim of this study was to quantitatively analyse our own and published maps of Atta foraging patterns on a meta-level, to provide a solid basis for further studies. Therefore, we used three methodological approaches to describe different aspects of these dendritic systems: fractal analysis for space occupancy and spatial complexity, circular analysis for directional orientation and navigation in space and time and conventional statistics for general analysis. The following aspects of Atta foraging trail systems were analysed: (1) permanence in space and time, (2) plasticity in space and time and (3) differences between young and mature colonies. The results were coherent and allowed us to present an integrating hypothesis that accounts for the complex pattern of foraging in Atta.

\section{METHODS}

\section{Studied colonies and their locations}

A total of seven leaf-cutting ant colonies were included in the study (Table 1). We grouped colonies into two age classes following Bitancourt (1941) resulting in three young (nest surface area $c .0 .2-0.3 \mathrm{~m}^{2}$ ) and four mature colonies (nest surface area $c .60-100 \mathrm{~m}^{2}$ ). The three young colonies (Y-1, Y-2, Y-3) and the first mature colony (M-1) belonged to the species Atta sexdens and were located in the periphery of mature pristine forest (Forget et al. 1999) near the Paracou field station $\left(5^{\circ} 18^{\prime} \mathrm{N}\right.$; $52^{\circ} 53^{\prime} \mathrm{W}$ ) in French Guiana (FG). These colonies were

Table 1. The studied Atta colonies from Brazil, Barro Colorado Island (BCI) and French Guiana (FG): Colony: Colony age class ( $\mathrm{Y}=$ young, $\mathrm{M}=$ mature) - colony number; T: Total study period (d); N: Number of observation days (d); I: Interval between observations (d); FA: Foraging activity with $\mathrm{d}=$ diurnal and $\mathrm{n}=$ nocturnal. Colonies $\mathrm{M}-4$ and $\mathrm{M}-3$ are taken from Vasconcelos (1990) and Farji-Brener \& Sierra (1993), respectively.

\begin{tabular}{lllrrrl}
\hline Colony & \multicolumn{1}{c}{ Species } & \multicolumn{1}{c}{ Location } & T & N & I & FA \\
\hline Y-1 & A. sexdens L. & Paracou, FG & 47 & 17 & $2-3$ & d \\
Y-2 & A. sexdens & Paracou, FG & 47 & 17 & $2-3$ & d \\
Y-3 & A. sexdens & Paracou, FG & 47 & 17 & $2-3$ & d \\
M-1 & A. sexdens & Paracou, FG & 53 & 16 & $2-3$ & d/n \\
M-2 & A. colombica Guérin & BCI, Panama & 349 & 126 & $2-3$ & d \\
M-3 & A. cephalotes & BCI, Panama & 7 & 7 & 1 & d \\
M-4 & A. cephalotes & Manaus, Brazil & 320 & 49 & $6-10$ & $\mathrm{n}$ \\
\hline
\end{tabular}

observed from January to March 2000. The second mature colony (M-2) belonged to the species A. colombica (Wirth et al. 1997) and was situated in a remnant of old forest near the research station of the Smithsonian Tropical Research Institute on Barro Colorado Island (BCI) in the Republic of Panama $\left(9^{\circ} 09^{\prime} \mathrm{N} ; 79^{\circ} 51^{\prime} \mathrm{W}\right)$. Field observations of this colony were conducted from June 1993 to June 1994. Two other adult colonies (M-3, M-4) belonging to the species A. cephalotes were derived from the literature. One was mapped during 7 consecutive observation days on BCI (Farji-Brener \& Sierra 1993) and the other was monitored in a primary terra-firme forest north of Manaus (Brazil) between July 1985 and January 1986 as well as between September 1986 and March 1987 (colony C1 in Vasconcelos 1990). All sites show tropical climate and are classified in the Holdridge life zone system (Holdridge 1947) as tropical moist forests. Annual precipitations at the three sites were: Manaus $2.1 \mathrm{~m}$, BCI: $2.6 \mathrm{~m}$ and Paracou $3.0 \mathrm{~m}$, each with a pronounced dry and wet season (Forget 1996, Rand \& Rand 1982, Ribeiro 1976).

Voucher specimens of the colonies are deposited at the University of Bielefeld (M-2) and at the University of Kaiserslautern, Germany (Y-1, 2, 3 and M-1).

\section{Monitoring and mapping of foraging trails}

Foraging trails of the three young colonies Y-1, -2 and -3 and the two mature colonies $\mathrm{M}-1$ and $\mathrm{M}-2$ were monitored at 2-3 dintervals, resulting in the total observation times from 47 to $349 \mathrm{~d}$ (Table 1). Surveys of the foraging trails were done around the activity peaks of each colony. Compass bearing and length of existing recruitment trails, as well as of the corresponding cutting site or the location where ants ascended into the canopy (in the following referred to as 'foraging sites') were mapped by flagging the trail at intervals of $7.5 \mathrm{~m}$ in mature and $0.75 \mathrm{~m}$ in young colonies. This difference was due to an adjustment of the measuring scale to the spatial scale at which Atta colonies of different life stages forage and resulted in an estimated precision of $\pm 2 \mathrm{~m}$ for mature and $\pm 0.2 \mathrm{~m}$ for young colonies. Leaf sources for young colonies were defined as plant individuals or resource patches that were connected with a distinct trail and where cutting and carrying activity occurred within an observation time of at least $15 \mathrm{~min}$. In contrast, leaf sources of mature colonies were considered if cutting activity ( $>0.5$ laden ants $\mathrm{min}^{-1}$ ) was detectable within 2 min of observation.

Maps of the foraging trail systems were generated using the software package Corel Draw 8.0 (Corel Corporation, Ottawa, Canada). These maps were arranged to show the foraging trails and leaf sources for every single observation day (hereafter referred to as 'progressive maps') or for 
observation periods of several days, weeks or months ('cumulative maps'). For M-2, however, the progressive maps present observations accumulated on a monthly scale. Trail distribution data taken from Farji-Brener \& Sierra (1993) allowed an analysis on a daily scale over 7 observation days, whereas in Vasconcelos (1990) only one cumulative map over the total observation period was available. An index 'maximum degree of trail branching' was estimated for progressive trail maps by counting all trail branchings starting from the corresponding nest entrances and following the trail to its outermost leaf source. Likewise the 'linear foraging distance' was estimated by measuring the direct line between the centre of the nest and a given foraging site.

\section{Fractal analysis}

The spatial occupancy of trails was analysed by the well-established concept of fractal or scaling analysis. This methodology describes not only the geometry and the behaviour, i.e. the distribution in space and the dynamics in time, but in many cases also the causal origin and generation of complex systems (Avnir 1992, Halley et al. 2004, Kenkel \& Walker 1996, Mandelbrot 1983). Describing patterns in a two-dimensional space, the fractal dimension of different objects ranges from 0.0 (point), 1.0 (line) and 2.0 (plane) (Mandelbrot 1983) and is thus a useful tool to measure spatial complexity of foraging paths, as shown previously for similar problems (Bolton \& Boddy 1993, Fourcassiè et al. 1992, Rodriguez-Iturbe \& Rinaldo 2001). The two-dimensional distribution of foraging trails was analysed by calculating the fractal pure box-counting dimension $\left(\mathrm{D}_{\mathrm{f}}\right)$ with the programme FracTAK (Knoch 2002). Therefore, trail maps were converted to a two-dimensional pixelized dual-value image, by setting trails to a value of 1 and the background to a value of 0 . A measuring grid of squares with the side length $L_{B}$ was placed on top of the two-dimensional grid containing the trail map and the squares containing grids with trail value $1\left(\mathrm{~N}_{\mathrm{B}}\right)$ were counted.

$\mathrm{D}_{\mathrm{f}}$ was calculated from the negative exponent in the scaling relation between the number of boxes $N_{B}$ (i.e. area occupied by trails $A_{B}\left(L_{B}\right)$ ) and the side length of the boxes $\mathrm{L}_{\mathrm{B}}: \mathrm{N}_{\mathrm{B}} \sim \mathrm{L}_{\mathrm{B}}{ }^{-\mathrm{Df}}$ (i.e. area of the measuring grid occupied by trails $\left.A_{B}\left(L_{B}\right)=N_{B} \times L_{B}{ }^{2}\right)$. Since the analysed foraging trail systems are spatially limited objects, $D_{\mathrm{f}}$ was determined using the following fraction of the scaling region: 0.01 (corresponds to trail diameter) and 0.7 (total object size). Overlaying trail maps with a measuring grid may lead to errors, e.g. when the grid lines accidentally match trails. Therefore $\mathrm{N}_{\mathrm{B}}$ depends on the initial start position of the measuring grid. By shifting and turning the grid containing the trail maps, this bias could be reduced as indicated by a standard error for $D_{f}<0.01$. Since the standard error grows with $\mathrm{L}_{B}$, the number of twists and turns $S_{B}$ was chosen to be $S_{B}=$ abs $\left(0.1 \times L_{B}\right)$. To fulfil the assumption of power-law relationship between scale and occupancy over a reasonable number of scales (Halley et al. 2004), we took the broadest possible region to integrate over as many scaling regions as possible. However, some values for $D_{f}$ were thus $<1$. Considering a smaller region would have resulted in $\mathrm{D}_{\mathrm{f}}$ values $>1.0$. In terms of interpretation these values of $D_{f}<1.0$ should therefore be seen as $D_{\mathrm{f}}=1.0$.

As $D_{f}$ was significantly correlated with the corresponding number of foraging sites (Spearman Rank correlation: $\mathrm{N}=79, \mathrm{R}=0.871, \mathrm{P}<0.001$ ), newly discovered leaf sources $(\mathrm{N}=71, \mathrm{R}=0.746, \mathrm{P}<0.001)$, and trail branchings $(\mathrm{N}=80, \mathrm{R}=0.773, \mathrm{P}<0.001)$, it can be considered an integral indicator of the variability of the number of foraging sites and the resulting number of trail branchings.

Correlation analysis between $\mathrm{D}_{\mathrm{f}}$ and the trail length measured as the log number of pixels allowed us to assess whether newly established trails lead to an increased complexity of the foraging system. To give an example, doubling the length of a one-dimensional line does not change its occupancy or complexity in space, i.e. it is still one dimensional. However, arranging two one-dimensional lines to form a cross increases the space occupancy and complexity of the object with the dimensionality becoming $>1$.

\section{Circular statistics}

The directional orientation of Atta foraging activity was analysed using circular statistics following the methods described in Batschelet (1981) with the aid of the software Oriana 1.06 (Kovach Computing Services, Pentraeth, UK). For each colony and time period, the mapped foraging sites were grouped into $10^{\circ}$-sectors around the centre of the nest entrances. For each sample the statistics shown include sample size $(\mathrm{N})$, the mean angle $(\alpha)$ related to the geographical north, the length of the mean vector (r) as a measure of the concentration of foraging sites (directions) around the mean angle, the 95\% confidence interval $( \pm \delta)$ and the P-value for Rayleigh's uniformity test.

\section{Linear statistics}

Seasonal differences among individual colonies were assessed by comparing wet and dry season values of the analysed foraging features with t-tests for independent samples. The relationship between $\mathrm{D}_{\mathrm{f}}$ and parameters 
such as the number of foraging sites, the number of newly tapped leaf sources and the number of trail branchings were analysed with Spearman Rank correlation. All analyses of linear statistics were performed using SPSS 10.0 software (SPSS Inc., Chicago, IL, USA).

\section{RESULTS}

\section{Permanence of the trail systems in space and time}

Cumulative trail maps (Figure 1) revealed that large sections of the potentially available forest area in the vicinity of the nest (i.e. 'home range') were not subjected to any foraging activity for days, weeks and even months. This was clearly visible in all colonies and independent of age class and species, except for one young $A$. sexdens colony (Y-3), whose trail map indicated a wider exploration of its home range (Figure 1c). Strikingly, even after $1 \mathrm{y}$, no foraging activity could be observed between the principal axes of colonies M-2 (A. colombica) and M-4 (A. cephalotes). As previously shown by an inventory of the potential home range of $\mathrm{M}-2$, the ants ignored these areas despite the presence of tree species that were generally preferred by the colony (Wirth et al. 2003). Foraging activity of young colonies clustered around one (Y-1, Y-2) or two main directions (Y-3), whereas mature colonies preferred to forage within two (M-3), three (M-1) or four (M-2, M-4) well-defined, principal foraging sectors (Figure 1).

The fractal analysis of the cumulative maps also implied limited spatial exploration of the available plant resources within the foraging range of the colonies. A stepwise accumulation of foraging maps from the first to the last observation day resulted in a saturation of the cumulative $\mathrm{D}_{\mathrm{f}}$ clearly $<2.0$ in both young and mature colonies (Figure 2). To characterize the saturation plateau, a logarithmic regression was fitted to this cumulative $D_{\mathrm{f}}$ with a fit quality of $\mathrm{R}^{2}$ ranging from 0.77 to 0.98 in young and 0.72 and 0.97 in mature colonies. Thus, only parts of the potential home range served as foraging grounds. A foraging strategy aiming at covering the entire foraging range would not have resulted in a quasistationary plateau with $\mathrm{D}_{\mathrm{f}}<2.0$, but would have ranged around $\mathrm{D}_{\mathrm{f}}=2.0$ accounting for the relative isotropy of the foraging ground (Figure 2).

The circular statistics (Rayleigh's uniformity test) applied to the same maps (Figure 1), resulted in the rejection of uniformity of the distribution of host plants around the nests for six of the seven colonies analysed (Table 2). Only colony Y-1, the youngest colony included in the study, showed a more homogeneous spatial distribution of foraging sites (Rayleigh test: $\mathrm{N}=38$, $\mathrm{P}=0.086$ ).
All three methodologies applied (visual inspection, fractal analysis and circular statistics) revealed that foraging Atta ants use a static trunk trail system as a frozen physical memory of the spatial distribution of previously exploited host plants. The use of such trunk trails may presumably last over time periods longer than the ones here observed.

\section{Plasticity of the trail systems in space and time}

The course of trail branching of each colony during the study period indicated that high-order trails are subject to an increased degree of spatial and temporal plasticity both on a daily and monthly scale. In contrast, low-order trails (i.e. trunk trails) usually remained unchanged. In fact, several trunk trails were used during the whole study period, and in colony M-2 some of them lasted longer than $1 \mathrm{y}$ (Wirth et al. 2003). Trails of a higher order were absent in young colonies (Figure 3). Here, spatiotemporal plasticity was high in primary trails, suggesting that these trails fulfil the same function as high-order trails of mature colonies. The temporal progression of the fractal dimension of Atta foraging trail systems demonstrated a substantial variation of $D_{f}$ for both days and months (Figure 2). $\mathrm{D}_{\mathrm{f}}$ was tightly linked to the corresponding trail length with all correlation coefficients $\geq 0.7$ (Figure 4). This strong relationship suggests that the majority of newly established trails directly increased the complexity of the foraging system, since otherwise $\mathrm{D}_{\mathrm{f}}$ would have remained unchanged.

The observed temporal variation of $D_{\mathrm{f}}$ was partly due to seasonal influences on the trail systems (Figure 2): M-2, the colony with the longest total observation time, exhibited a peak of progressive $\mathrm{D}_{\mathrm{f}}$ during the 5 th and 6th survey month which was the peak of the wet season in September/October and a clear depression of $D_{\mathrm{f}}$ during the 9th and 10th observation month, i.e. the peak of the dry season in February/March. Even though this decrease of the progressive $D_{\mathrm{f}}$ from wet $(1.15 \pm 0.09)$ to dry season (1.13 \pm 0.07$)$ was not statistically significant, the number of simultaneously used foraging sites as well as the number of new leaf sources tapped significantly decreased for this mature colony (t-test: $\mathrm{P}<0.05$ for both parameters). The mature A. sexdens colony (M-1) showed a significant decrease in new leaf sources, foraging sites and trail branchings from wet to dry season (t-test: $\mathrm{P}<0.05$, respectively). Among the three young A. sexdens colonies, the number of foraging sites increased from wet to dry season ( $t$-test: $\mathrm{P}<0.05$ ), yet no statistical difference in either the number of new leaf sources tapped or the progressive fractal dimension between the two seasons could be detected.

Additionally, one case can be reported where the foraging pattern was demonstrably influenced by 
(a)

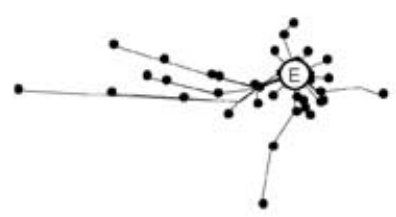

(d)

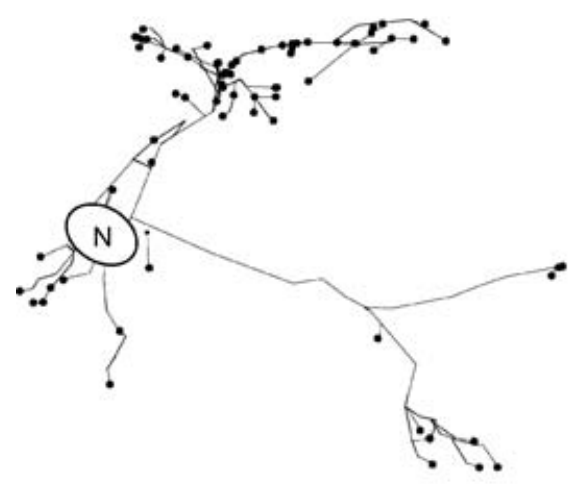

(f)
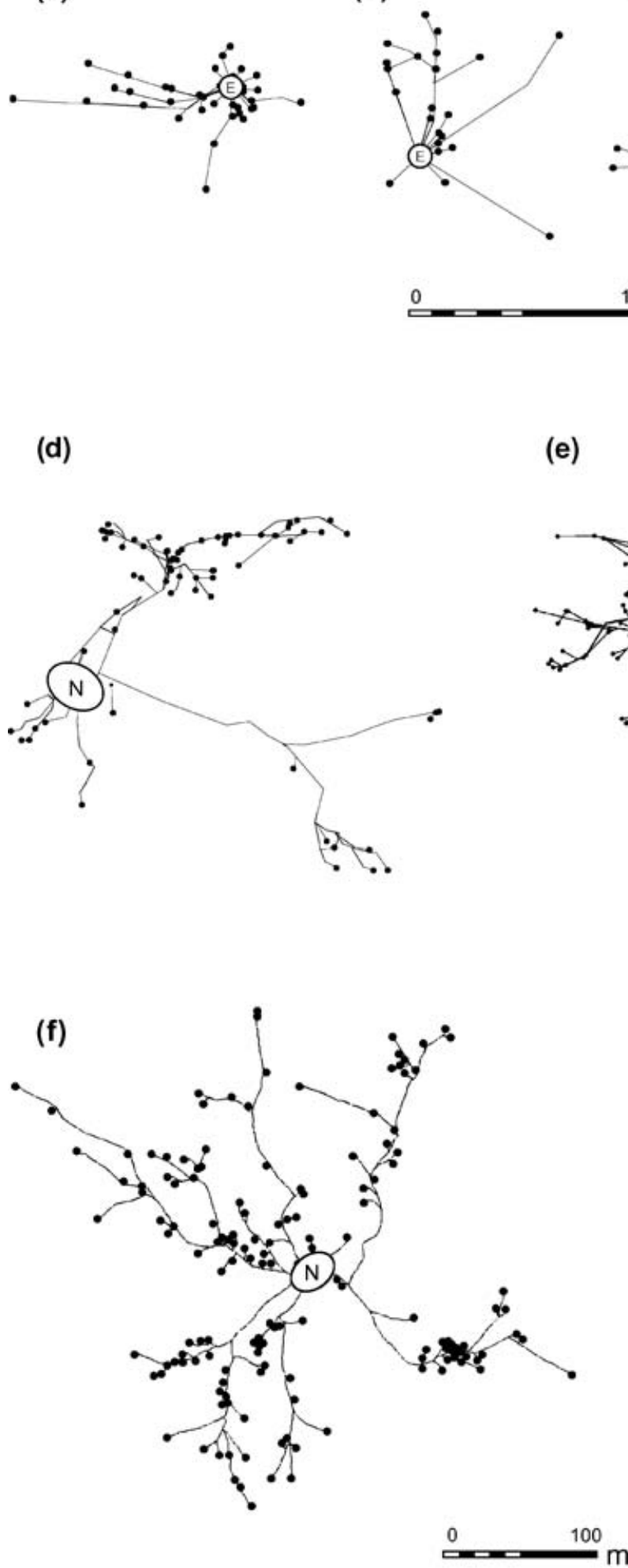

(e) (c)
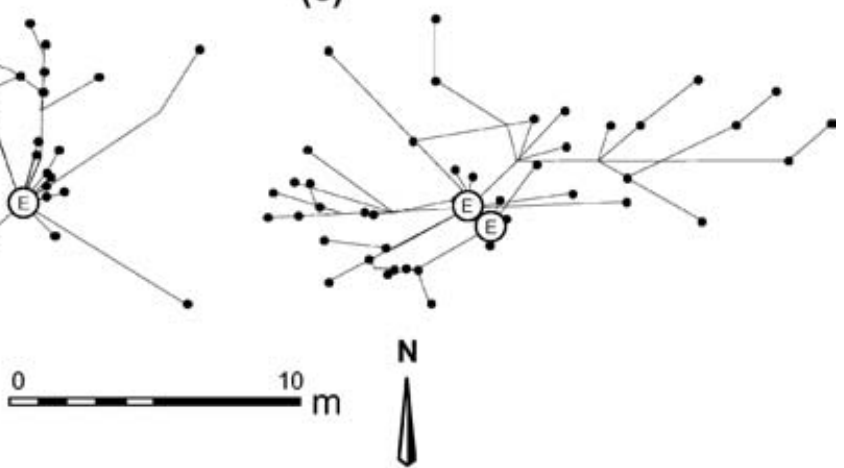

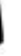

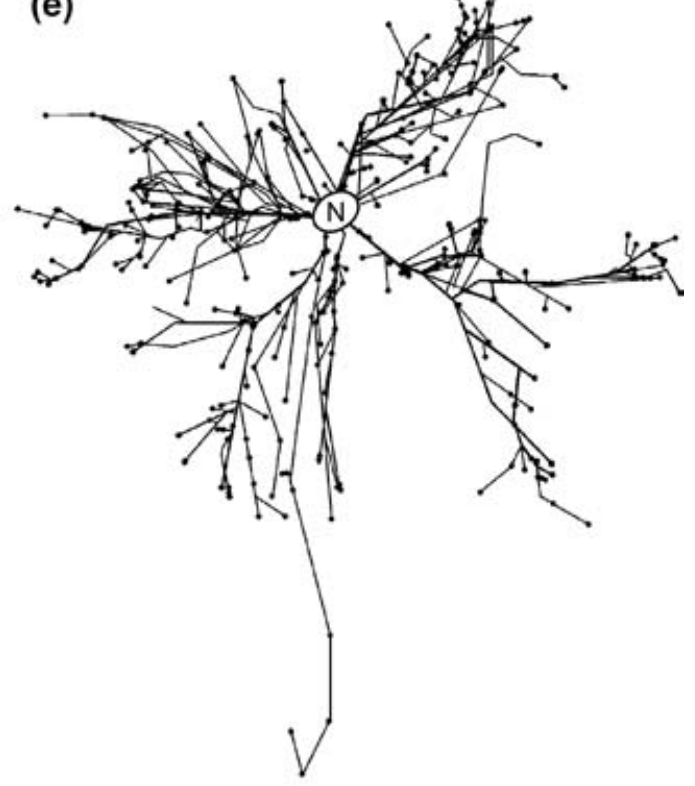

(g)

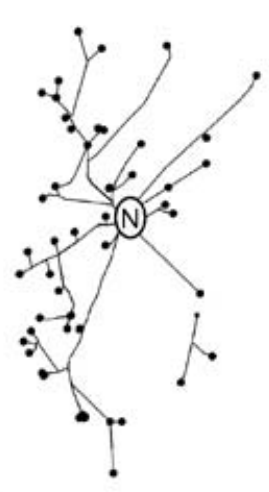

$\mathrm{N}$

1

Figure 1. Cumulative maps of all Atta study colonies. Lines represent foraging trails and dots the corresponding leaf sources. The first row shows young colonies with (E) indicating nest entrances: (a) Y-1, (b) Y-2, (c) Y-3. The second and third row show mature colonies with (N) defining nest areas: (d) M-1, (e) M-2 (Wirth et al. 2003), (f) M-4 (Vasconcelos 1990), and (g) M-3 (Farji-Brener \& Sierra 1993). The upper scale refers to the young and the lower to mature colonies. 
Table 2. Orientation of foraging activity in all studied Atta colonies. Sample size (N, i.e. number of foraging sites), length of mean vector (r), mean angle $(\alpha)$ in degrees with respect to the geographic north, 95\% confidence intervals $( \pm \delta)$ in degrees and P-values for the Rayleigh test of uniformity.

\begin{tabular}{lrcrrc}
\hline Colony & $\mathrm{N}$ & $\mathrm{r}$ & $\alpha\left(^{\circ}\right)$ & $\pm \delta\left(^{\circ}\right)$ & $\mathrm{P}$ \\
\hline Y-1 & 38 & 0.250 & 225 & 100 & 0.086 \\
Y-2 & 28 & 0.658 & 24 & 40 & 0.000 \\
Y-3 & 39 & 0.281 & 314 & 88 & 0.045 \\
M-1 & 63 & 0.630 & 61 & 28 & 0.000 \\
M-2 & 485 & 0.103 & 186 & 69 & 0.006 \\
M-3 & 48 & 0.299 & 255 & 75 & 0.013 \\
M-4 & 148 & 0.167 & 279 & 78 & 0.016 \\
\hline
\end{tabular}

interspecific predation. The reduction of $\mathrm{D}_{\mathrm{f}}$ at the 18th observation day of colony Y-1 (Figure 2) was due to a raid by army ants (Eciton sp.). These ants were observed entering this Atta nest and leaving it again with a considerable number of ant larvae held in their mandibles.

Altogether, the analyses revealed a spatially and temporally highly variable distribution of foraging trails around permanent trunk trails in mature colonies, and around nest entrances in young colonies. Both season and interspecific predation influenced the distribution and branching pattern of foraging trails in young and mature colonies (Figure 2).

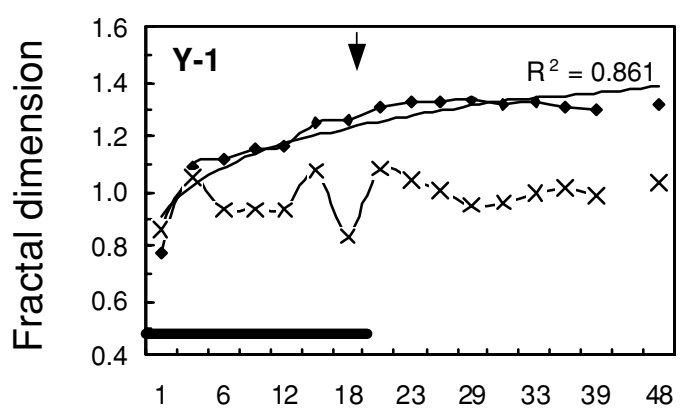

Day of survey

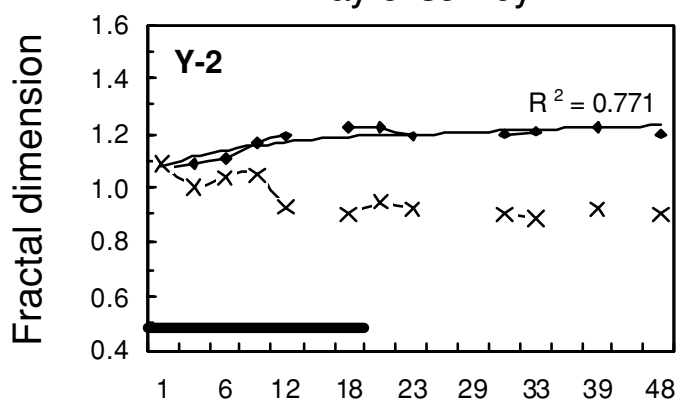

Day of survey

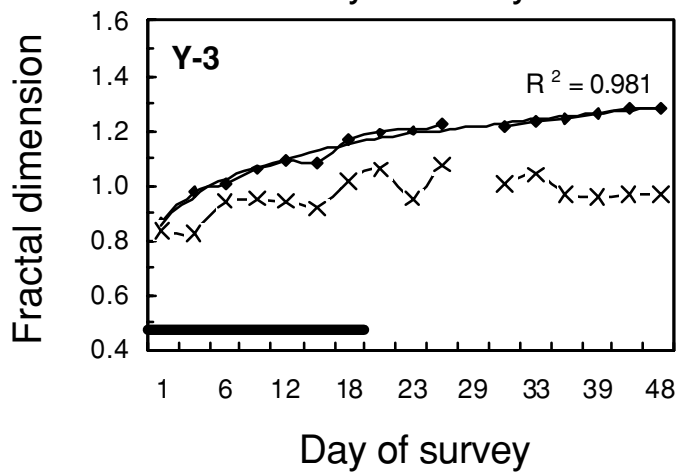

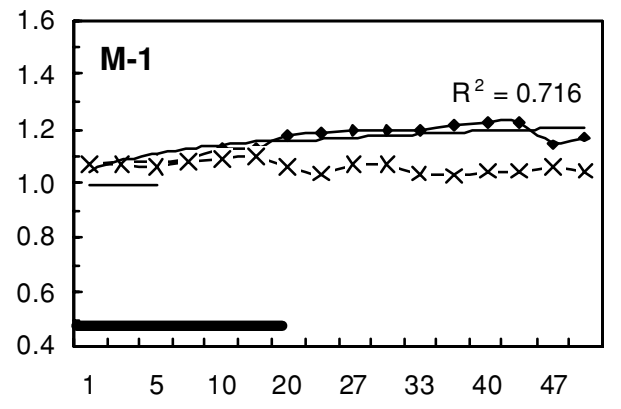

Day of survey
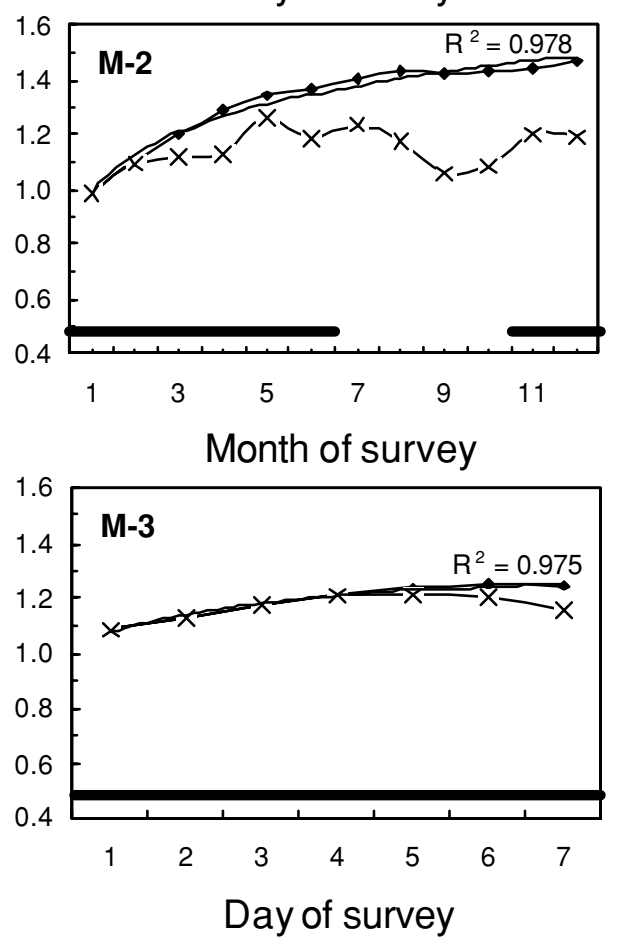

Figure 2. Progressive $(\times)$ and cumulative $(\bullet)$ temporal development of the fractal dimension ( $\left.\mathrm{D}_{\mathrm{f}}\right)$ of young (left) and mature (right) colonies of Atta colombica (M-2), A. cephalotes (M-3) and A. sexdens (all other). Note that the corresponding trail maps were recorded on a daily (M-3), 2-3 d (M-1 and Y-1, 2, 3) or monthly scale (M-2). Gaps between data points correspond to no foraging activity at the respective day due to e.g. rainfall. A logarithmic curve was fitted to the cumulative $\mathrm{D}_{\mathrm{f}}$ data and the $\mathrm{R}^{2}$ values refer to these regressions. The bold black lines indicate the duration of the wet season and the arrow in Y-1 the attack of an army ant raid of Eciton sp. 

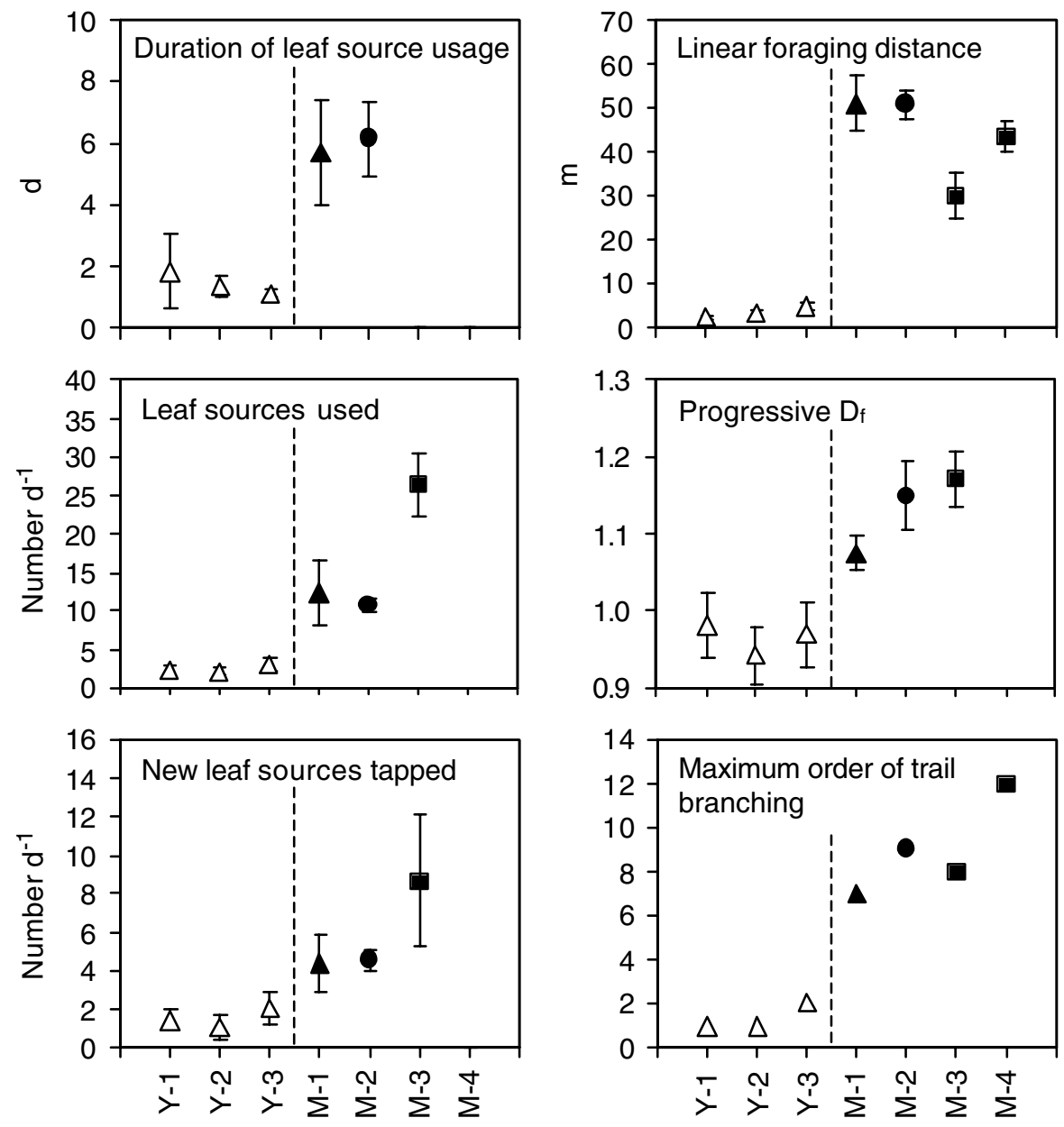

Figure 3. Comparison of different features of the foraging systems of all analysed Atta colonies. Mean values ( $\pm 95 \%$ confidence interval) of six parameters of three young $(\triangle)$ and one mature $(\boldsymbol{\Delta})$ Atta sexdens colony as well as of a mature A. colombica $(\bullet)$ and two A. cephalotes colonies $(\boldsymbol{\square})$ are displayed.

\section{Young versus mature Atta colonies}

The following analyses were focused on intraspecific comparisons between young and mature colonies of $A$. sexdens as their trail maps corresponded in terms of season and survey schedule. To test whether the observed trends also hold true for other Atta species, the adult colonies of A. sexdens, A. colombica and A. cephalotes were compared.

The comparison of life stages implied substantial differences between the foraging patterns of young and mature A. sexdens colonies. Trail systems of young $A$. sexdens colonies exhibited lower degrees of trail branching and reduced numbers of leaf sources used per observation day (Figure 3). Trails of these colonies maximally truncated to a second order, whereas trail branching in the conspecific mature colony reached up to an order of seven. Age-related spatial complexity of the foraging system was also evident from the fractal analysis with mean progressive $\mathrm{D}_{\mathrm{f}}$ values being lower in young colonies compared with the mature colony.
Young colonies also revealed a higher temporal variability of trail usage. Mean trail persistence measured as the duration of leaf source usage (i.e. number of days) in young colonies was about a third of that in the mature colony (Figure 3). At the same time, young colonies frequently changed their preferred foraging orientation, whereas the adult $A$. sexdens colony showed a high directional fidelity of foraging (Figure 5). Both the linear foraging distance (Figure 3) and the overall size of the foraging systems in young colonies (Figures 1 ) were about ten times smaller compared to mature colonies. Moreover, young colonies were never observed harvesting leaves from a tree, bush or any other woody species (only once colony Y-2 harvested leaves of a branch that broke off a small tree). The spectrum of host plants used by these colonies almost entirely consisted of small herbaceous species. In contrast, $61 \%$ of the plants attacked by colony M-2 and $48 \%$ of the plants attacked by colony M-1 had a dbh $>5 \mathrm{~cm}$, illustrating that a large proportion of the leaves harvested in adult colonies were derived from larger leaf sources. 


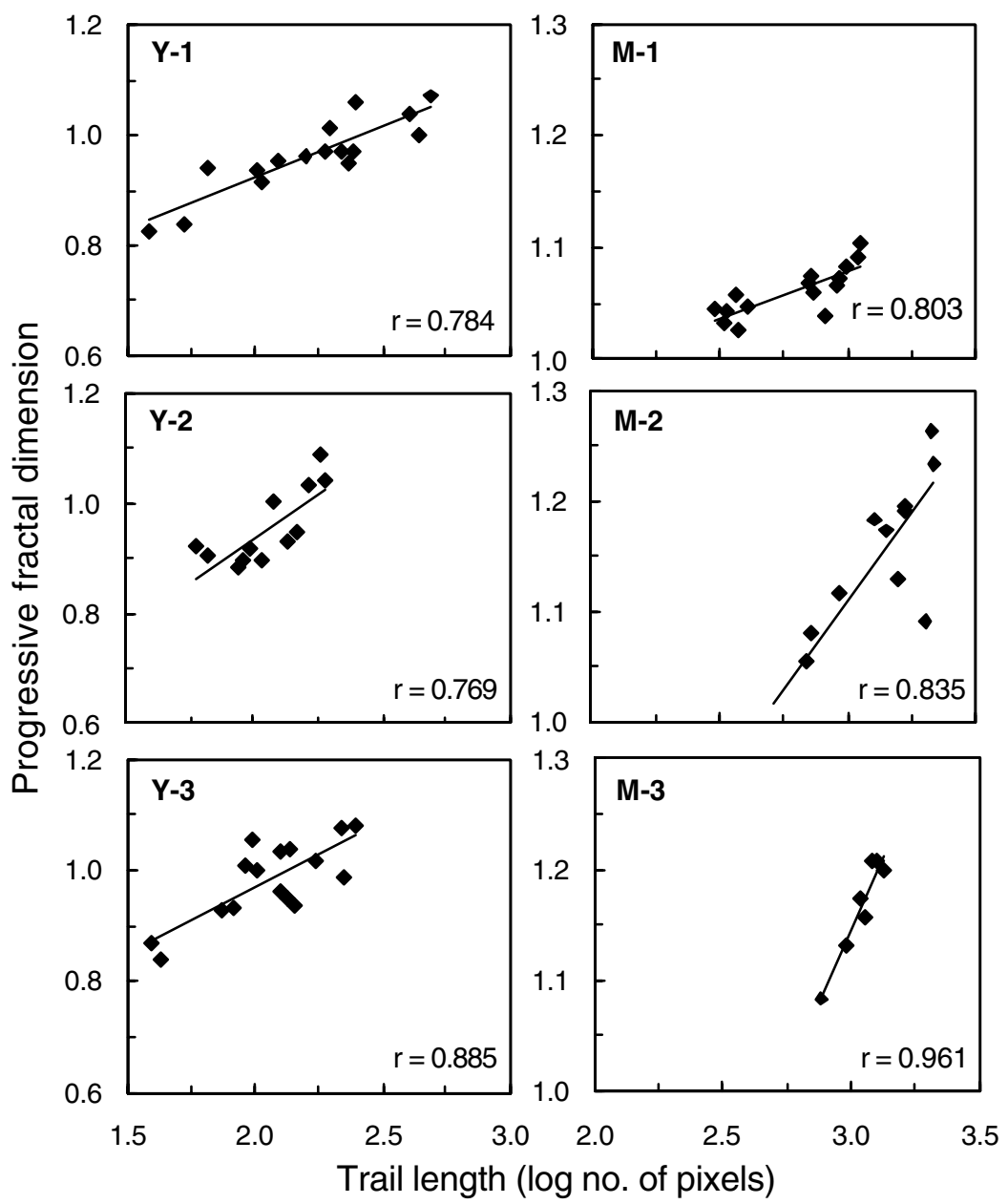

Figure 4. Correlations between progressive $\mathrm{D}_{\mathrm{f}}$ and trail length for young (left) and adult (right) colonies of Atta colombica (M-2), A. cephalotes (M-3) and A. sexdens (all other). The corresponding correlation coefficients ( $\mathrm{r}$ ) are displayed in each graph.

Interspecific comparisons among the mature colonies (Figure 3) revealed strong similarities between colony M-1 (A. sexdens) and M-2 (A. colombica), with the mean progressive $D_{\mathrm{f}}$ being the only parameter that was clearly higher for colony $\mathrm{M}-2$. Foraging features in adult $A$. cephalotes were as follows: colony M-3 used and opened up more leaf sources per observation day than did either M-1 or M-2. Furthermore, the linear foraging distance of both A. cephalotes colonies (M-3 and M-4) was shorter than in mature colonies of the congeneric species (Figure 3). The mean progressive $D_{\mathrm{f}}$ of colony $\mathrm{M}-3$ resembled that of $\mathrm{M}-2$.

\section{DISCUSSION}

\section{Permanence of the trail systems in space and time}

The results obtained here describe a trail system that directs Atta foragers to previously exploited leaf sources and thus determines main foraging directions. Long-term trail formation could be visualized by cumulative trail maps, showing that in nearly all studied Atta colonies foraging activity was restricted to certain sectors of their potential home ranges. Conversely, large sections outside these main foraging sectors were left virtually untouched by the ants and did not experience any harvesting activity for days, weeks or months. In some cases, this pattern remained stable for more than $1 \mathrm{y}(\mathrm{M}-2$ and $\mathrm{M}-4$; see also Wirth et al. 2003). The maximum time span of leafsource utilization was less than $1 \mathrm{y}$, since trunk trails never led directly to leaf sources. These observations also held true for two of three young colonies indicating that such preferred foraging directions were already present at an early life stage.

A restriction of the leaf harvest to distinct foraging sectors was strongly supported by the rapid quasisaturation of cumulative $\mathrm{D}_{\mathrm{f}}$ curves of all colonies in the course of the survey. If, in an alternative scenario, the colonies used their complete home range for foraging (e.g. in a rotating leaf harvest as proposed by FarjiBrener \& Sierra 1993), it would require the frequent establishment of new trails to cover the whole nest 


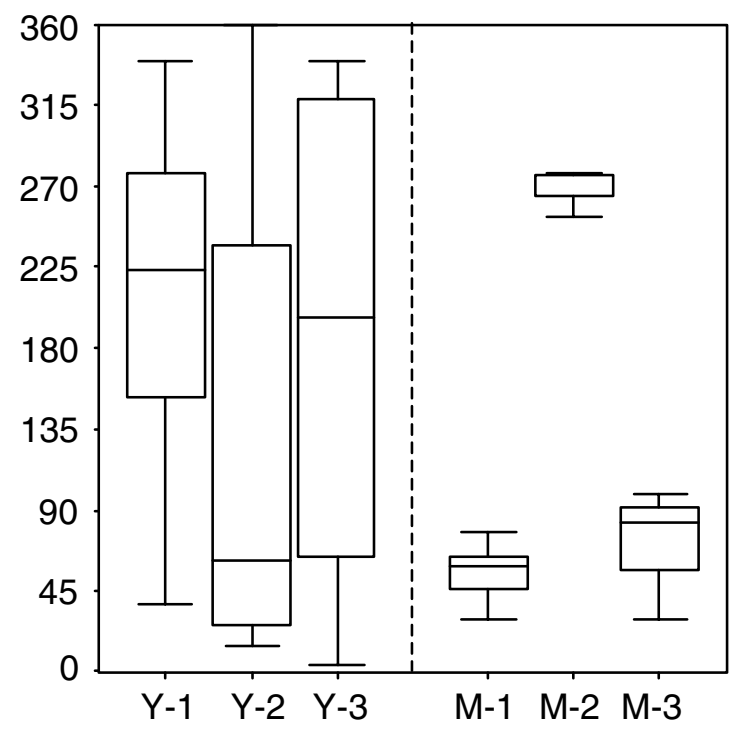

Figure 5. Assessment of temporal changes in the geometrical distribution of exploited leaf sources by calculating mean angles for each observation day. Data are presented as box-and-whisker plots, which indicate the overall distribution of the data by showing the first and third quartile (lower and upper margin of the box), the median (line within the box) and the $5 \%$ as well as the $95 \%$ percentile. Colonies of the two age classes young (left side) and mature (right side) are shown. Mean angles were calculated on a daily (A-3), 2-3 d (A-1 and Y-1, 2 and 3) or monthly scale (A-2).

vicinity. Consequently, $\mathrm{D}_{\mathrm{f}}$ should increase constantly for a longer period until the entire home range had been covered with foraging trails and result in a saturation plateau at $\mathrm{D}_{\mathrm{f}}=2$. The fact that the studied colonies reached a saturation plateau after a few days or weeks of observation with $\mathrm{D}_{\mathrm{f}}$ values $<2$, supports the interpretation of a spatially restricted leaf harvest. Saturation of $D_{f}$ took longer in colony A-2 because trail maps were only available on a monthly basis and between-month differences in the foraging pattern are smaller than those between days.

The circular statistics applied to the cumulative maps revealed a directional and non-homogeneous leaf harvest for six of seven colonies. Only colony Y-1, seemingly the youngest colony observed, showed a rather uniform distribution of the exploited leaf sources around the nest. This may suggest that young colonies are in an exploratory phase prior to the establishment of major trunk trails. In fact, this explanation corresponds to the known phenomenon that definite trails do not occur before a colony reaches a certain size (Weber 1966). In contrast to the above conclusion, Farji-Brener \& Sierra (1993) postulated an unpredictable harvesting pattern covering the complete home range of a colony. This may be due to the short observation time $(7 \mathrm{~d})$ and the fact that their study on BCI (Panama) was performed in October, a period when colonies abandon and establish new trails more frequently due to frequent rainfall (Wirth et al. 2003).

The persistence of trunk trail usage in Atta may not only be explained with the distribution of highquality resources within the potential home range of a colony (Fowler \& Stiles 1980, Howard 2001). We have evidence that the zones between foraging sectors provide equivalent supply of resources. In fact, the leaf harvest of colony A-2 was limited to about a third of the tree individuals theoretically accessible within its home range, although several of the ignored tree species were generally preferred by this colony (Wirth et al. 2003, see also Cherrett 1983). We therefore propose that major foraging axes may be established in the earlier history of an individual colony and largely persist during later stages of its life.

\section{Plasticity of the trail systems in space and time}

It is not yet properly understood why the switching of host plants and the construction of new trails occurs so frequently. Possible explanations are: (1) spatiotemporal heterogeneity of host plant quality caused by phenological changes (Hubbell et al. 1984, Rockwood 1976) or induction of chemical plant defences (de Oliveira et al. 2004, Howard 1990), (2) varying nutritive demands of colonies through time (Cherrett 1972a,b), and (3) interspecific interactions such as the protection of host plants by associated ant species (Vasconcelos \& Casimiro 1997, Wetterer 1994, Wirth et al. 1997). Even if predation of army ants on Atta has been reported previously (Powell \& Clark 2004, Sanchez-Pena \& Mueller 2002, Swartz 1998, Weber 1972), this study provided first evidence that predation can alter foraging behaviour in Atta.

The dynamic construction of new trails may also be modulated by abiotic disturbances like rain or litterfall. In fact, our data indicate that in the wet season, foraging systems of adult colonies were characterized by higher dynamics and an increased spatial complexity compared with the dry season. This may be caused by a destruction of subsidiary trails through heavy rainfalls, resulting in a higher frequency of new trail establishment. The interruption of on-going foraging when precipitation reaches certain intensity (Cherrett 1968, Hodgson 1955, Wirth et al. 1997) forces Atta ants to concentrate their foraging activities on the immediate vicinity of wellestablished trunk trails. In contrast, young colonies used significantly more leaf sources per observation day in the dry, compared with the wet season. Allocating a reduced number of workers to a small number of leaf sources in the wet season could reflect a risk-averse mode of foraging in vulnerable young colonies, as workers may easily get lost in heavy rains. 


\section{Young versus mature Atta colonies}

Besides the above-mentioned similarities between the foraging patterns of young and mature colonies, a comparison between the two age classes of $A$. sexdens colonies revealed some striking differences. The foraging trail systems of young colonies tended to be less complex and host plants were switched more frequently, resulting in a reduced duration of trail utilization. Furthermore, young colonies foraged on a smaller spatial scale with shorter distances covered and fewer leaf sources used.

Smaller colonies generally foraged in straight lines from the nest, whereas mature colonies frequently changed directions. Since the recordings of directional changes had been adjusted to the spatial scale of foraging, this observation can be interpreted as an age effect. Topologically, straight connections from the nest to the host plants should become more difficult to find with increasing foraging area, because foragers are more likely to encounter physical obstacles.

The observed foraging features may reflect age-related feeding preferences in Atta. The diet of the young colonies mainly comprised herbaceous plants. The rapid depletion of such small leaf sources explains the above-mentioned frequent switches of host plants. In contrast, mature colonies showed a clear preference for larger trees, an observation that is well known from the literature (Cherrett 1968, Rockwood \& Hubbell 1987, Wirth et al. 2003). This preference for larger trees may simply reflect increased availability of plant biomass that allows prolonged exploitation of individual resource patches. This results at the same time in an increased persistence of the access routes that lead to these patches.

\section{Optimal foraging}

Foraging organisms should optimize the quality of the harvested material in relation to time and energy spent for foraging (Pyke et al. 1977). Foraging trail systems of Atta may thus be constrained by a trade-off between trail establishment (and maintenance) and searching efficiency for high-quality resources. Indeed, our findings support such a model of optimal foraging. In mature colonies, persistent trunk trails served as starting points for searching the trail vicinity for palatable leaf sources, thereby permitting a flexible coverage of a considerable area within major foraging sectors. Considering trailclearing a significant investment in time and energy (Lugo et al. 1973, Shepherd 1982), this observation may be interpreted as a cost-saving strategy. These findings accord with earlier studies, suggesting that foraging effort, scouting behaviour, and food transport are concentrated on and nearby existing trails (Farji-Brener \& Sierra 1998, Reed \& Cherrett 1990, Shepherd 1982). Ephemeral trails of a higher order were absent in young colonies. Here, their function was fulfilled by primary trails.

The parameters $D_{f}$ and trail length were tightly linked together. In other words, newly established trails appeared as trail junctions rather than prolongations of existing trails. The maximum linear foraging distance from the nest is limited (Cherrett 1983, Reed \& Cherrett 1990). An extension of the foraging system therefore leads to an increased complexity within this boundary (e.g. by trail ramification). Obviously, the costs of establishing new trails have to be outweighed by the benefit provided by the access to high quality resources.

\section{Conclusions}

The combination of fractal analysis with circular and conventional statistics proved to be complementary and helpful in elucidating different aspects of spatiotemporal foraging patterns of Atta colonies. The picture emerging from this meta-analysis stimulated the following hypotheses and provides new insights into the complex system of Atta foraging:

(1) Foraging in young colonies of the species Atta sexdens is characterized by an opportunistic exploitation of herbaceous species in the immediate vicinity of their nest. Mainly short and unramified primary trails are used to directly connect the nest entrance with host plants. The quick exploitation of these plants results in frequent directional changes of the foraging trails. However, in the long run directional preferences of foraging become increasingly apparent.

(2) With advancing age of a colony, population size, demand of plant biomass and spatial scale of foraging area increase. This results in a higher probability for trail ramifications and thus favours a self-organizing increase in trail system complexity.

(3) Extending preferred directions by establishing primary trunk trails may determine future foraging patterns, because maintaining an existing system of trunk trails has lower energetic costs than establishing completely new foraging trails (Howard 2001). Consequently, the branching pattern of foraging trails results from interacting factors such as initial foraging experience and energetic constraints.

(4) The increased spatial complexity of foraging in adult Atta colonies is limited to existing trunk trails that open up only a portion of the potential foraging ranges. These quasi-permanent, high-cost trunk trails serve as starting points for low-cost subsidiary trails which are highly flexible in space and time.

Despite the fact that the present meta-analysis was limited to a relatively small data set, it represents the largest compilation and analysis of Atta foraging trail 
maps available to date. The consistent picture that emerged underpins the view that the foraging trail system in Atta is a general phenomenon that seems to overcome species borders. The observed results represent a starting point for future studies that should (1) verify whether the proposed hypothesis is generally applicable to Atta species in seasonal rain forest habitats and (2) further elucidate intrinsic and extrinsic variables determining the variability of Atta foraging trails in space and time.

\section{ACKNOWLEDGEMENTS}

The authors thank Alejandro G. Farji-Brener and Heraldo F. Vasconcelos for providing additional information. We especially thank Silvia Schmidt for enthusiastic help during field work and Pascal Petronelli for sharing his expertise. Comments by Alejandro G. Farji-Brener, Jerome J. Howard, Martin Heil, Birgit Schulze, Egbert G. Leigh as well as two anonymous referees on previous versions of the manuscript are gratefully acknowledged. This research was supported by a grant of the European Tropical Large-Scale Facility (DG/FJ/033/98) and the German Research Foundation, Bonn (SFB 251, University of Würzburg).

\section{LITERATURE CITED}

AVNIR, D. 1992. The fractal approach to heterogeneous chemistry-surfaces, colloids, polymers. John Wiley \& Sons, Chichester. 460 pp.

BATSCHELET, E. 1981. Circular statistics in biology. Vol. 1. Academic Press, London. 371 pp.

BITANCOURT, A. 1941. Expressão matematica do crescimento de formigueiros de Atta sexdens rupropilosa representado pelo aumento do numero de olheiros. Archivos do Instituto Biológico São Paulo 12:229-236.

BOLTON, R. G. \&BODDY, L. 1993. Characterization of the spatial aspects of foraging mycelial cord systems using fractal geometry. Mycological Research 97:762-768.

CHERRETT, J. M. 1968. The foraging behaviour of Atta cephalotes L. (Hymenoptera, Formicidae) I. Foraging pattern and plant species attacked in tropical rain forest. Journal of Animal Ecology 37:387403.

CHERRETT, J. M. 1972a. Chemical aspects of plant attack by leaf cutting ants. Pp. 13-24 in Harbourne, J. B. (ed.). Phytochemical ecology. Academic Press, London.

CHERRETT, J. M. 1972b. Some factors involved in the selection of vegetable substrate by Atta cephalotes (L.) (Hymenoptera: Formicidae) in tropical rain forest. Journal of Animal Ecology 41:647-660.

CHERRETT, J. M. 1983. Resource conservation by the leaf-cutting ant Atta cephalotes in tropical rain forest. Pp. 253-263 in Sutton, S. L., Whitmore, T. C. \& Chadwick A. C. (eds.). Tropical Rain Forest: Ecology and Management. Blackwell Scientific Publications, Oxford. 512 pp.

DE OLIVEIRA, H. G., LACERDA, F. G., MARINHO, C. G. \& DELLA LUCIA, T. M. 2004. Atta sexdens rubropilosa attractiveness to eucalyptus plants previously attacked or not by Thyrinteina arnobia. Pesquisa Agropecuaria Brasileira 39:285-287.

FARJI-BRENER, A. G. \& SIERRA, C. 1993. Distribution of attacked plants along trails in leaf-cutting ants (Hymenoptera: Formicidae): consequences in territorial strategies. Revista de Biología Tropical 41:891-896.

FARJI-BRENER, A. G. \& SIERRA, C. 1998. The role of trunk trails in the scouting activity of the leaf-cutting ant Atta cephalotes. Ecoscience 5:271-274.

FARJI-BRENER, A. G. \& SILVA, J. F. 1995. Leaf-cutting ants and forest groves in a tropical parkland savanna of Venezuela: facilitated succession? Journal of Tropical Ecology 11:651-669.

FORGET, P. M. 1996. Removal of seeds Carapa procera (Meliaceae) by rodents and their fate in rainforest in French Guiana. Journal of Tropical Ecology 12:751-761.

FORGET, P. M., MERCIER, F. \& COLLINET, F. 1999. Spatial patterns of two rodent-dispersed rain forest trees Carapa procera (Meliaceae) and Vouacapoua americana (Caesalpiniaceae) at Paracou, French Guiana. Journal of Tropical Ecology 15:301-313.

FOURCASSIÈ, V., COUGHLIN, D. \& TRANIELLO, J. F. A. 1992. Fractal analysis of search behaviour in ants. Naturwissenschaften 79:8789.

FOWLER, H. G. \& ROBINSON, S. W. 1979. Foraging by Atta sexdens (Formicida: Attini): seasonal patterns, caste and efficiency. Ecological Entomology 4:239-247.

FOWLER, H. G. \& STILES, E. W. 1980. Conservative resource management by leaf-cutting ants? The role of foraging territories and trails, and environmental patchiness. Sociobiology 5:2541.

HALLEY, J. M., HARTLEY, S., KALLIMANIS, A. S., KUNIN, W. E., LENNON, J. J. \& SGARDELIS, S. P. 2004. Uses and abuses of fractal methodology in ecology. Ecology Letters 7:254-271.

HODGSON, E. S. 1955. An ecological study of the behavior of the leafcutting ant Atta cephalotes. Ecology 36:293-304.

HOLDRIDGE, L. R. 1947. Determination of world plant formations from simple climatic data. Science 105:367-368.

HÖLLDOBLER, B. \& LUMSDEN, C. J. 1980. Territorial strategies in ants. Science 210:732-739.

HOWARD, J. J. 1990. Infidelity of leaf-cutting ants to host plants: resource heterogeneity or defense induction? Oecologia 82:394401.

HOWARD, J. J. 2001. Cost of trail construction and maintenance in the leaf-cutting ant Atta colombica. Behavioural Ecology and Sociobiology 49:348-356.

HUBBELL, S. P., HOWARD, J. J. \& WIEMER, D. F. 1984. Chemical leaf repellency to an attine ant: seasonal distribution among potential host plant species. Ecology 65:1067-1076.

KENKEL, N. C. \& WALKER, D. J. 1996. Fractals in biological sciences. Coenoses 11:77-100.

KNOCH, T. A. 2002. Approaching the three-dimensional organization of the human genome: structural-, scaling- and dynamic-properties in the simulation of interphase chromosomes and cell nuclei, long-range correlations in complete genomes, in vivo quantification of the chromatin distribution, construct conversions in simultaneous co-transfections. TAK Press, Mannheim. 88 pp. 
LITTLEDYKE, M. \& CHERRETT, J. M. 1976. Direct ingestion of plant sap from cut leaves by the leaf-cutting ants Atta cephalotes (L.) and Acromyrmex octospinosus (Reich) (Formicidae, Attini). Bulletin of Entomological Research 66:205-217.

LUGO, A. E., FARNWORTH, E. G., POOL, G., JEREZ, P. \& KAUFMANN, G. 1973. The impact of the leaf-cutter ant Atta colombica on the energy flow of a tropical wet forest. Ecology 54:1292-1301.

MANDELBROT, B. B. 1983. The fractal geometry of nature. Freeman and Company, New York. 480 pp.

POWELL, S. \& CLARK, E. 2004. Combat between large derived societies: a subterranean army ant established as a predator of mature leafcutting ant colonies. Insectes Sociaux 51:342-351.

PYKE, G., PULLIAM, H. R. \& CHARNOV, G. L. 1977. Optimal foraging: a selective review of theory and tests. Quarterly Review of Biology 52:137-154.

RAND, A. S. \& RAND, W. M. 1982. Variation in rainfall on Barro Colorado Island. Pp. 47-59 in Windsor, D. M. (ed.). The ecology of a tropical forest: seasonal rhythms and long-term changes. Smithsonian Institution Press, Washington DC.

RAO, M., TERBORGH, J. \& NUÑEZ, P. 2001. Increased herbivory in forest isolates: implications for plant community structure and composition. Conservation Biology 15:624-633.

REED, J. \& CHERRETT, J. M. 1990. Foraging strategies and vegetation exploitation in the leaf-cutting ant Atta cephalotes (L.) - a preliminary simulation model. Pp. 355-366 in Vander Meer, R., Jaffe, K. \& Cedeno, A. (eds.). Applied myrmecology - A world perspective, Westview Press, Boulder.

RIBEIRO, M. N. G. 1976. Aspectos climatológicos de Manaus. Acta Amazonica 6:229-233.

ROCKWOOD, L. L. 1976. Plant selection and foraging patterns in two species of leaf-cutting ants (Atta). Ecology 57:48-61.

ROCKWOOD, L. L. \& HUBBELL, S. P. 1987. Host plant selection, diet, diversity, and optimal foraging in a tropical leaf-cutting ant. Oecologia 74:55-61.
RODRIGUEZ-ITURBE, I. \& RINALDO, A. 2001. Fractal river basins: chance and self-organization. Cambridge University Press, Cambridge. 564 pp.

SANCHEZ-PENA, S. R. \& MUELLER, U. G. 2002. A nocturnal raid of Nomamyrmex army ants on Atta leaf-cutting ants in Tamaulipas, Mexico. Southwestern Entomologist 27:221-224.

SHEPHERD, J. D. 1982. Trunk trails and the searching strategy of a leaf-cutter ant, Atta colombica. Behavioral Ecology and Sociobiology 11:77-84.

STRADLING, D. J. 1978. The influence of size on foraging in the ant Atta cephalotes, and the effect of some plant defence mechanisms. Journal of Animal Ecology 47:173-188.

SWARTZ, M. B. 1998. Predation on an Atta cephalotes colony by an army ant Nomamyrmex esenbeckii. Biotropica 30:682-684.

VASCONCELOS, H. L. 1990. Foraging activity of two species of leafcutting ants (Atta) in a primary forest of the central Amazon. Insectes Sociaux 37:131-146.

VASCONCELOS, H. L. \& CASIMIRO, A. B. 1997. Influence of Azteca alfari ants on the exploitation of Cecropia trees by a leaf-cutting ant. Biotropica 29:84-92.

WEBER, N. A. 1966. Fungus growing ants. Science 153:587-604.

WEBER, N. A. 1972.Gardening ants: the Attines, Memoirs of the American Philosophical Society, Vol. 92. American Philosophical Society, Philadelphia.

WETTERER, J. K. 1994. Attack by Paraponera clavata prevents herbivory by the leaf-cutting ant, Atta cephalotes. Biotropica 26:462465.

WIRTH, R., BEYSCHLAG, W., RYEL, R. J. \& HÖLLDOBLER, B. 1997. Annual foraging of the leaf-cutting ant Atta colombica in a semideciduous rain forest in Panama. Journal of Tropical Ecology 13:741-757.

WIRTH, R., BEYSCHLAG, W., RYEL, R., HERZ, H. \& HÖLLDOBLER, B. 2003. The herbivory of leaf-cutting ants. A case study on Atta colombica in the tropical rainforest of Panama. Vol. 164. Springer Verlag, Berlin. $240 \mathrm{pp}$. 